\title{
DIFFERENT CLINICAL OUTCOME IN CORONARY ARTERY BYPASS WITH SINGLE AND SEQUENTIAL VEIN GRAFTS: A FIFTEEN-YEAR FOLLOW-UP STUDY
}

\author{
B. L. van Brussel, MD \\ H. W. M. Plokker, MD, $\mathrm{PhD}^{\mathrm{b}}$ \\ A. A. Voors, $\mathrm{MD}^{\mathrm{b}}$ \\ J. M. P. G. Ernst, MD, $\mathrm{PhD}^{\mathrm{b}}$ \\ J. C. Kelder, $\mathrm{MD}^{\mathrm{c}}$ \\ P. J. Knaepen, $\mathrm{MD}^{\mathrm{d}}$ \\ F. E. E. Vermeulen, MD
}

\begin{abstract}
Objective: In trying to answer the question about the controversial use of sequential grafts, we determined the long-term clinical outcome of patients in whom coronary artery bypass was done with different types of vein grafts. Methods: A total of 428 consecutive patients who underwent isolated coronary artery bypass with vein grafts between April 1, 1976, and April 1, 1977, were prospectively observed. In these patients three groups could be defined with single grafts only, sequential grafts only, and combined single and sequential grafts. Follow-up was $99.8 \%$ complete and averaged 15.4 years for the survivors. The Kaplan-Meier method and multivariate analysis done with the Cox regression model were used for survival, myocardial infarction, reintervention, and "any event." Results: Perioperative mortality and perioperative myocardial infarction rate were not statistically different among the three groups. During follow-up more myocardial infarctions (hazard ratio: $2.06 ; 95 \%$ confidence interval: 1.08 to 3.93; $p=0.0293$ ) or any events (hazard ratio: $1.54 ; 95 \%$ confidence interval: 1.01 to $2.36 ; p=0.0450$ ) occurred in patients with sequential grafts only than in patients with single grafts only. Conclusion: Although more complete revascularization was obtained in patients with sequential vein grafts only, more events during a 15-year follow-up occurred in these patients than in patients with single vein grafts only. (J Thorac Cardiovasc Surg 1996;112:69-78)
\end{abstract}

In 1971 coronary artery bypass surgery with sequential vein grafts was introduced by Flemma and associates. ${ }^{1}$ Use of these grafts made it easier to achieve complete revascularization. Nevertheless, the use of sequential vein grafts has been the subject of controversy because a severe stenosis of the main stem of a graft may jeopardize a greater part of the myocardium than is true if single vein grafts are used.

In the present era of coronary artery surgery the internal thoracic artery is preferred because of its higher patency rate. However, in many patients with arterial conduits, coronary artery bypass with single

From the Department of Cardiology, Diaconessenhuis, ${ }^{\text {a }}$ Eindhoven, and the Departments of Cardiology, ${ }^{\mathrm{b}}$ Clinical Epidemiology, ${ }^{c}$ and Cardiothoracic Surgery, ${ }^{\mathrm{d}}$ St. Antonius Hospital, Nieuwegein, The Netherlands.

Received for publication Feb. 15, 1995; accepted for publication Oct. 3, 1995.

Address for reprints: B. L. van Brussel, MD, Diaconessenhuis, Department of Cardiology, PO Box 90.052, 5600 PD Eindhoven, The Netherlands.

Copyright (C) 1996 by Mosby-Year Book, Inc.

$0022-5223 / 96 \$ 5.00+0 \quad \mathbf{1 2 / 1 / 6 9 6 5 7}$ or sequential vein grafts (or both) will continue to be used to achieve complete coronary revascularization. Therefore, even today it remains important to study the long-term clinical outcome as a function of the type of vein grafts used during coronary bypass. The literature contains only a few studies on this subject. $^{2,3}$

We report the long-term results of three different patient groups (patients with single vein grafts only [group I] or sequential vein grafts only [group II] and patients with combined single and sequential vein grafts [group III]) belonging to a consecutive patient group who underwent isolated coronary artery bypass grafting with only vein grafts in 1 year and whom we followed up prospectively.

\section{Methods}

The angiographic and clinical definitions and the patient group have been described in detail before. ${ }^{4}$ In brief, the study group consisted of 428 consecutive patients, 383 men and 45 women, with an average age of 52.6 years (range 20 to 74 years) who underwent isolated coronary artery bypass operations with vein grafts between April 1, 1976, and April 1, 1977, at the St. Antonius Hospital, Nieuwegein, The Netherlands. Nearly half of the patients 
$(49 \%)$ had had a myocardial infarction and more than $2 \%$ had a history of heart failure before the operation. In $61 \%$ of the study population the severity of preoperative angina was class III or IV according to the Canadian Cardiovascular Society, in $48 \%$ three-vessel disease was demonstrated at coronary angiography, and in $12 \%$ left main coronary artery disease was also present. In $21 \%$ of the study group left ventricular function was moderately or severely diminished. In $26 \%$ of the patients unstable angina pectoris was the indication for surgical therapy.

Our study population was divided into three groups according to the grafts used during the operation: patients with single vein grafts only (group I, $n=188$ ), patients with sequential vein grafts only (group II, $n=60$ ), and patients with combined single and sequential vein grafts (group III, $n=180$ ).

Surgical technique. Intermittent aortic occlusion with moderate hypothermia $\left(25^{\circ}\right.$ to $\left.28^{\circ} \mathrm{C}\right)$ alternating with deep hypothermia $\left(20^{\circ}\right.$ to $\left.22^{\circ} \mathrm{C}\right)$ at clamping was used for the operations. Single coronary artery bypass grafts with or without sequential grafts were placed. Only the lower leg saphenous vein was used for the grafts. Side-to-side anastomoses were used in this early experience of sequential grafting-longitudinal side-to-side vein-to-artery anastomoses in $51 \%$, diamond-shaped anastomoses in $22 \%$, oblique anastomoses in $19 \%$, and other types of anastomoses in $8 \%$. All end-to-side anastomoses were constructed longitudinally. An average of 3.2 coronary anastomoses per patient was made. A left ventricular aneurysm resection was performed in 25 patients. Complete revascularization, defined as revascularization of all coronary arteries with a diameter of at least $1 \mathrm{~mm}$ and a stenosis of $50 \%$ or more supplying a vital left ventricular wall segment, was achieved in $78 \%$ of the study group.

Follow-up and data collection. Several follow-up methods were used simultaneously to provide the most complete information possible. All patients were followed up at the hospital's outpatient clinic or the outpatient clinic of the referring cardiologists (or at both sites) on the anniversary of the operation. The common "closing data" method was used in 1992 to close follow-up of all patients. Because of the combined follow-up methods, all patients except one, who went abroad and was lost to follow-up 7 years after operation, were traced for the common closing date of April 1, 1992. Exact information about the clinical events studied was obtained in all patients. Our follow-up was $99.8 \%$ complete. The mean duration of follow-up for the survivors was 15.4 years.

Statistical analysis. The following clinical events were studied: overall mortality, acute myocardial infarction, and reintervention (reoperation or percutaneous transluminal coronary angioplasty, or both). Patients not surviving the operation were excluded from statistical analysis. Therefore 415 patients were followed up. Perioperative myocardial infarction was likewise not included in statistical analysis of myocardial infarction during follow-up.

To identify prognostic covariates that might have explained differences among the groups, we estimated survival curves by the method described by Kaplan and Meier $^{5}$ from the baseline variables as described in Table I. Postoperative events are calculated from life-table analysis and presented as percentages \pm standard deviation.
Differences in survival times between groups were calculated by the log rank and the Wilcoxon tests (SAS. PROC.LIFETEST, SAS Institute, Inc., Chicago, Ill.). All variables with a significance level of $p<0.10$ in at least one of these univariate tests were selected for entry in a multivariate proportional hazards model as proposed by $\operatorname{Cox}^{6}$ (COX.PROC.PHREG, SAS Institute, Inc., Chicago, IIl.). The variables age and gender but also all other important clinical variables were always included. Proportionality of hazards was checked by means of the log cumulative hazard plot (log cumulative hazard plotted against log time) for each of the variables entered in the model. This plot will convert the vertical proportionality of the original plots into a vertical equidistance, therefore permitting visual assessment. All curves were approximately parallel and equidistant vertically for the various levels of the variable. We concluded that the underlying hazards were proportional and the Cox model was appropriate. ${ }^{7}$ Subsequently, we were able to predict the independent influence of the single or sequential technique on different cardiac events in this population. The risk of one group having a clinical event compared with the risk in another group is reflected by the hazard ratio.

\section{Results}

General results. In Table I the presence of the different baseline variables in the three patient groups and the results of the univariate analysis among these three groups are given. In group I (patients with single vein grafts only) the lowest mean number of distal anastomoses per patient was found. In group II (patients with sequential vein grafts only) the highest percentage of patients had complete revascularization. In group III (patients with single and sequential vein grafts) a more severe degree of coronary atherosclerosis was present at operation, because a high percentage of patients had three-vessel disease and left main coronary artery disease. There was a significant difference in the mean extracorporeal circulation time and in the mean extracorporeal circulation time per distal anastomosis among the three groups.

Mortality. Thirteen patients died during or within 30 days after the operation, seven patients belonging to group I (4\%) and six patients to group III $(3 \%)$. This difference in hospital mortality among the three patient groups was not statistically significant. (According to Fisher's exact method, two-sided for group I versus group II, group II versus group III, and group I versus group III, the $p$ values are, respectively, $0.20,0.34$, and 1.00.)

In group I the mortality was constant in the first 6 years after operation, with a mean annual mortality rate of $0.7 \%$. After these years mortality increased, especially from the tenth year after operation, with a 
Table 1. Baseline variables in patients with single grafts only (group I), sequential grafts only (group II), and both type of grafts (group III), as well as univariate data analysis ( $p$ values) between these groups

\begin{tabular}{|c|c|c|c|c|c|c|}
\hline & $\begin{array}{c}\text { Group I } \\
(n=181)\end{array}$ & $\begin{array}{c}I \leftrightarrow I I \\
(p)\end{array}$ & $\begin{array}{l}\text { Group II } \\
(n=60)\end{array}$ & $\begin{array}{c}I I \leftrightarrow I I I \\
(p)\end{array}$ & $\begin{array}{l}\text { Group III } \\
(n=174)\end{array}$ & $\begin{array}{c}I \leftrightarrow I I I \\
(p)\end{array}$ \\
\hline Age $>50 \mathrm{yr}$ & $62 \%$ & 0.90 & $62 \%$ & 0.26 & $71 \%$ & 0.08 \\
\hline Age $\leq$ & $38 \%$ & & $38 \%$ & & $29 \%$ & \\
\hline Female gender & $13 \%$ & 0.90 & $13 \%$ & 0.12 & $7 \%$ & 0.07 \\
\hline Previous myocardial infarction & $44 \%$ & 0.39 & $50 \%$ & 0.94 & $51 \%$ & 0.19 \\
\hline History of heart failure & $2 \%$ & 0.58 & - & 0.57 & $2 \%$ & 1.00 \\
\hline Family history of CAD & $8 \%$ & 0.92 & $8 \%$ & 0.70 & $7 \%$ & 0.25 \\
\hline \multicolumn{7}{|l|}{ Angina pectoris (CCS) } \\
\hline I & $2 \%$ & 0.74 & $2 \%$ & 0.97 & $3 \%$ & 0.25 \\
\hline II & $39 \%$ & & $37 \%$ & & $35 \%$ & \\
\hline III & $33 \%$ & & $40 \%$ & & $41 \%$ & \\
\hline IV & $27 \%$ & & $22 \%$ & & $21 \%$ & \\
\hline \multicolumn{7}{|l|}{ Number of diseased vessels } \\
\hline One & $25 \%$ & 0.98 & $30 \%$ & $<0.001$ & $1 \%$ & $<0.001$ \\
\hline Two & $45 \%$ & & $30 \%$ & & $29 \%$ & \\
\hline Three & $29 \%$ & & $40 \%$ & & $70 \%$ & \\
\hline Left main CAD & $8 \%$ & 1.00 & $8 \%$ & 0.08 & $18 \%$ & 0.004 \\
\hline Proximal stenosis LAD & $30 \%$ & 0.79 & $32 \%$ & 0.53 & $36 \%$ & 0.20 \\
\hline Coronary collateral circulation & $50 \%$ & 0.97 & $50 \%$ & 0.001 & $74 \%$ & $<0.001$ \\
\hline \multicolumn{7}{|l|}{ Left ventricular function } \\
\hline CASS score: $5-7$ & $69 \%$ & 0.14 & $60 \%$ & 0.48 & $61 \%$ & 0.26 \\
\hline CASS score: $8-10$ & $18 \%$ & & $17 \%$ & & $22 \%$ & \\
\hline CASS score: $>10$ & $13 \%$ & & $23 \%$ & & $17 \%$ & \\
\hline \multicolumn{7}{|l|}{ Obesity } \\
\hline Quetelet index $>25$ & $21 \%$ & 0.45 & $23 \%$ & 0.65 & $20 \%$ & 0.06 \\
\hline Quetelet index unknown & $6 \%$ & & $2 \%$ & & $1 \%$ & \\
\hline \multicolumn{7}{|l|}{ Hypercholesterolemia } \\
\hline$>6.5 \mathrm{mmol} / \mathrm{L}$ & $60 \%$ & 0.59 & $62 \%$ & 0.23 & $71 \%$ & 0.12 \\
\hline Unknown & $18 \%$ & & $22 \%$ & & $13 \%$ & \\
\hline \multicolumn{7}{|l|}{ Hypertriglyceridemia } \\
\hline$>2.0 \mathrm{mmol} / \mathrm{L}$ & $23 \%$ & 0.04 & $10 \%$ & 0.007 & $28 \%$ & 0.49 \\
\hline Unknown & $17 \%$ & & $28 \%$ & & $16 \%$ & \\
\hline \multicolumn{7}{|l|}{ Diabetes mellitus } \\
\hline Present & $2 \%$ & 1.00 & $2 \%$ & 1.00 & $2 \%$ & 1.00 \\
\hline Unknown & $24 \%$ & & $35 \%$ & & $12 \%$ & \\
\hline Hypertension & $12 \%$ & 0.37 & $17 \%$ & 0.59 & $14 \%$ & 0.65 \\
\hline \multicolumn{7}{|l|}{ Smoking } \\
\hline Yes & $41 \%$ & 0.35 & $40 \%$ & 0.65 & $40 \%$ & 0.83 \\
\hline Unknown & - & & $2 \%$ & & $1 \%$ & \\
\hline \multicolumn{7}{|l|}{ Indication for operation } \\
\hline Stable angina pectoris & $68 \%$ & 0.97 & $68 \%$ & 0.86 & $72 \%$ & 0.60 \\
\hline Unstable angina pectoris & $29 \%$ & & $28 \%$ & & $25 \%$ & \\
\hline Other & $3 \%$ & & $3 \%$ & & $4 \%$ & \\
\hline \multicolumn{7}{|l|}{ Number of distal anastomosis } \\
\hline$>3$ & $3 \%$ & $<0.001$ & $63 \%$ & 0.47 & $68 \%$ & $<0.001$ \\
\hline \multirow{2}{*}{\multicolumn{7}{|c|}{ Complete revascularization }} \\
\hline & & & & & & \\
\hline Yes & $75 \%$ & 0.006 & $92 \%$ & 0.013 & $67 \%$ & 0.68 \\
\hline No & $25 \%$ & & $8 \%$ & & $23 \%$ & \\
\hline Mean ECT $(\min )( \pm S D)$ & $82 \pm 40$ & $<0.001$ & $115 \pm 48$ & $<0.001$ & $138 \pm 44$ & $<0.001$ \\
\hline Mean ECT/DA $(\mathrm{min})( \pm \mathrm{SD})$ & $40 \pm 17$ & $<0.001$ & $31 \pm 7$ & 0.005 & $34 \pm 7$ & $<0.001$ \\
\hline
\end{tabular}

$C A D$, Coronary artery disease; $C C S$, Canadian Cardiovascular Society; $L A D$, left anterior descending artery; $C A S S$, Coronary Artery Surgery Study; $E C T$, extracorporeal circulation time; $D A$, distal anastomosis; $S D$, standard deviation. 


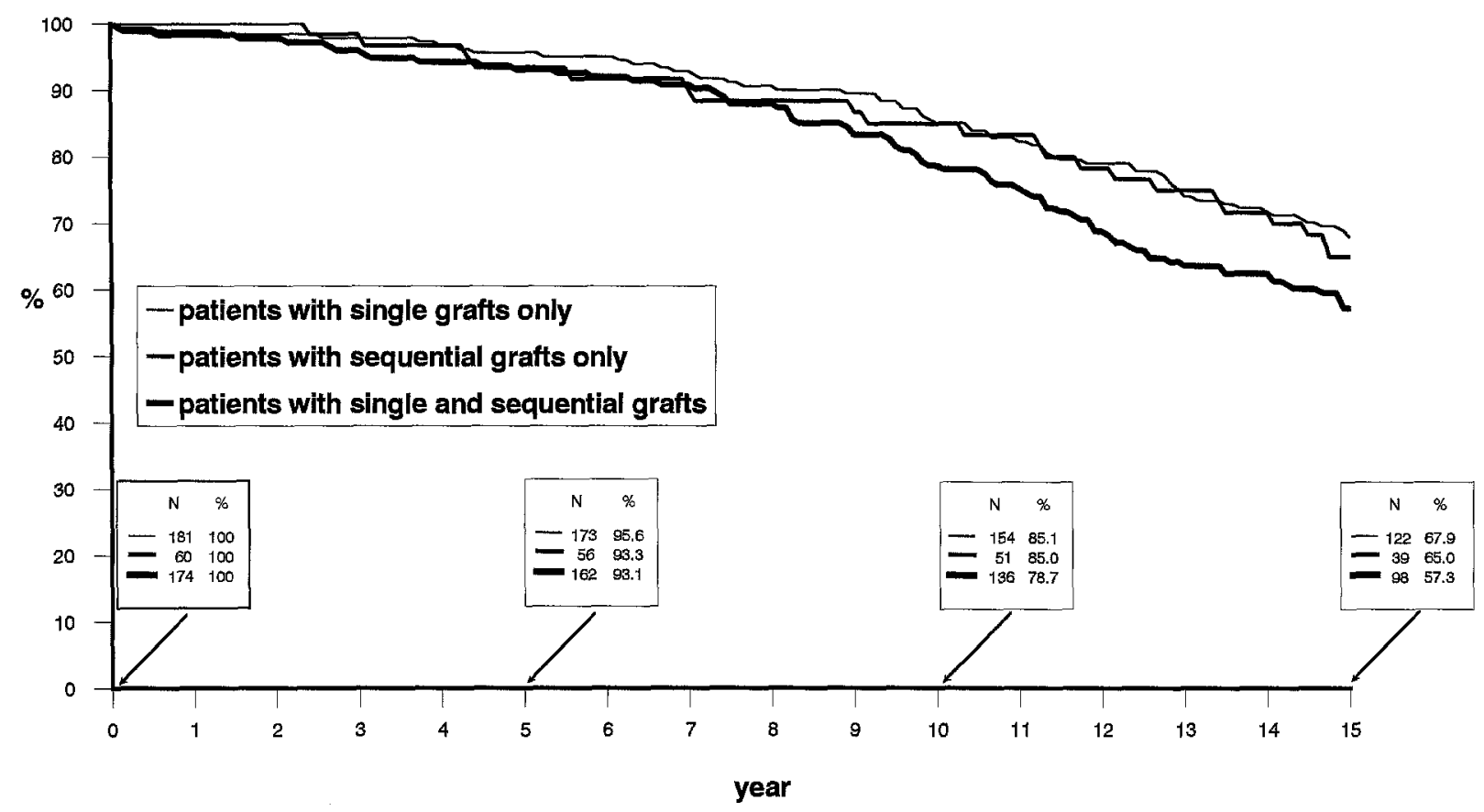

Fig. 1. Actuarial survival of patients with single grafts only, patients with sequential grafts only, and patients with single and sequential grafts.

mean annual mortality rate of $3 \%$. In group II mortality was constant in the first postoperative decade. The annual mean mortality rate was $1.5 \%$. In the twelfth year after operation mortality increased to a yearly mean of $4.5 \%$. Mortality was constant in group III in the first 7 years after operation, with a mean yearly mortality of $1.3 \%$. In the following years the annual mortality rose to a mean of $4.4 \%$. These figures lead to a 15 -year survival of $57.3 \% \pm 3.8 \%$. In groups I and II, 15 -year survivals were $67.9 \% \pm 3.5 \%$ and $65 \% \pm$ $6.2 \%$ (mean \pm standard deviation), respectively (Fig. 1).

Despite these differences among the three groups, the multivariate hazard ratio was close to 1 with no statistically significant differences; for example, a slight but not significantly increased risk for overall mortality was found in patients with sequential grafts only (group II) and in patients with single and sequential grafts (group III) as compared with patients with single grafts only (Table II).

Myocardial infarction. In 27 patients a myocardial infarction occurred within 30 days after operation. The perioperative myocardial infarction rates for groups I, II, and III were $7 \%, 2 \%$, and $7 \%$, respectively. These differences are statistically not significant. (According to Fisher's exact method, two-sided for group I versus group II, group II versus group III, and group I versus group III, the $p$ values are, respectively, $0.77,0.77$, and 1.00.)

In the first 5 years after operation the myocardial infarction rate was low in all three patient groups. Thereafter the mean annual myocardial infarction rate increased, especially in group II (to $3.2 \%$ ). In groups I and III the rates were $2 \%$ and $1.4 \%$, respectively. Fifteen years after the operation, $80.6 \% \pm 3.5 \%$ of group I, $66 \% \pm 7.1 \%$ of group II, and $78.3 \% \pm 3.9 \%$ of group III remained free from myocardial infarction. The occurrence of a myocardial infarction 15 years after operation, then, is nearly identical in patients of groups I and III, but an infarction occurs more frequently in patients of group II (sequential grafts only) (Fig. 2).

Multivariate analysis revealed a more than twofold increase in the risk of myocardial infarction during the follow-up period in patients belonging to group II than in patients belonging to group I (single grafts only). There was no statistically significant difference in the occurrence of myocardial infarction between the patients of group III versus those of group I and group II. (Table III).

Reintervention. In the first 6 to 7 years after operation the need for reintervention was small. This was true especially in group II patients, in 
whom the annual reintervention rate was $0.3 \%$. In the same period the reintervention rate was $0.7 \%$ for group I and $0.8 \%$ for group III. In the following years more reinterventions were required in all three groups. The rate for reintervention in those years was $3.3 \%$ for group I, $4.6 \%$ for group II, and $4.5 \%$ for group III. The actuarial freedom from reinterventions 15 years after operation was $66.3 \%$ $\pm 3.8 \%$ for group I, $56.7 \% \pm 7.3 \%$ for group II, and $58.9 \% \pm 4.5 \%$ for group III (Fig. 3). There seems to be a greater need for reintervention during follow-up for patients receiving sequential grafts exclusively or in combination with single grafts (groups II and III).

The hazard ratio detected by multivariate analysis among the three patient groups is nearly identical, however, and equals 1 . There is a small but not significantly greater risk for the need for reinterventions in both groups II and III as compared with group I (Table IV).

Any event (death, myocardial infarction, or reintervention). Most of the events occurred in patients with at least one sequential graft. The mean annual rate for the first 7 years after operation was $3.1 \%$ for group II compared with $2.4 \%$ for group III and $2.3 \%$ for group I. After 7 years the annual rate increased to $6.3 \%$ for group II and $6.5 \%$ for group III but to $5.2 \%$ for group I. The actuarial freedom from any event 15 years after the operation is $42 \% \pm 3.7 \%$ for group I, $28.3 \% \pm 5.8 \%$ for group II, and $31.3 \% \pm 3.5 \%$ for group III (Fig. 4).

In multivariate analysis, patients with exclusively sequential grafts have a small but nevertheless significantly higher risk for any event after coronary revascularization than do patients with single grafts only. The independent risk was more than 1.5 times greater for patients belonging to group II than for those in group I (Fig. 5). Although patients with single and sequential grafts seem more likely to need reintervention than do patients with single grafts only, in multivariate analysis this apparent trend was not statistically significant (Table V).

\section{Discussion}

On the introduction of sequential coronary grafting, Flemma and associates ${ }^{1}$ considered the decrease in extracorporeal circulation time but also the high flow representing "a most thorough and extensive myocardial revascularization" as the greatest advantages in relation to the surgical technique of single grafts. Flow in a graft is a major determinant of both early and late graft patency. ${ }^{8}$
Table II. Results of multivariate analysis for mortality

\begin{tabular}{llll}
\hline \multicolumn{1}{c}{ Factor } & HR & $95 \%$ CI & $\begin{array}{c}p \\
\text { Value }\end{array}$ \\
\hline $\begin{array}{l}\text { Sequential graft (base }= \\
\quad \text { single graft) }\end{array}$ & 1.19 & $0.73-1.94$ & 0.50 \\
$\begin{array}{l}\text { Single and sequential grafts } \\
\quad \text { base = single graft) }\end{array}$ & 1.10 & $0.76-1.60$ & 0.62 \\
$\begin{array}{l}\text { Single and sequential grafts } \\
\quad \text { (base = sequential) }\end{array}$ & 0.93 & $0.56-1.52$ & 0.76 \\
Age (>50 yr) & 1.73 & $1.19-2.51$ & 0.0041 \\
Gender & 1.20 & $0.71-2.05$ & 0.50 \\
History of AMI & 1.06 & $0.73-1.53$ & 0.77 \\
History of AMI unknown & 1.86 & $0.43-8.01$ & 0.40 \\
Two-vessel disease & 1.22 & $0.65-2.28$ & 0.54 \\
Three-vessel disease & 1.41 & $0.75-2.67$ & 0.29 \\
Left main coronary artery & 1.49 & $0.96-2.31$ & 0.08 \\
$\quad$ disease & & & \\
Proximal stenosis of LAD & 1.22 & $0.87-1.70$ & 0.25 \\
Coronary collateral circula- & 1.29 & $0.87-1.91$ & 0.21 \\
$\quad$ tion & & & \\
Left ventricular function & & & \\
$\quad$ CASS score: 8-10 & 1.41 & $0.93-2.14$ & 0.10 \\
$\quad$ CASS score: >10 & 2.03 & $1.34-3.08$ & 0.0009 \\
Hypertriglyceridemia & 1.25 & $0.86-1.83$ & 0.24 \\
Triglycerides unknown & 0.87 & $0.51-1.47$ & 0.59 \\
Diabetes mellitus & 1.68 & $0.65-4.36$ & 0.29 \\
Diabetes mellitus unknown & 0.79 & $0.47-1.33$ & 0.37 \\
\hline
\end{tabular}

HR, Hazard ratio, $C I$, confidence interval; $A M I$, acute myocardial infarction; $L A D$, left anterior descending artery; $C A S S$, Coronary Artery Surgery Study.

Flow and therefore graft patency depend on distal runoff. Thus it is useless to separately revascularize smaller coronary artery branches because in most cases they do not have adequate runoff to support these single grafts. ${ }^{9}$ If more than one coronary arterial communication is used along the graft course, the peripheral coronary resistance is less and flow should be increased. ${ }^{10}$ Through this higher flow the main bypass trunk stays open and may assist in maintaining patency of side-to-side anastomoses to arteries with a poor runoff. ${ }^{11}$ Even with this kind of operation a prophylactic graft might be used to protect a patient if sclerosis progresses. ${ }^{12}$ Although Sewell ${ }^{13}$ in 1978 doubted whether complete revascularization was useful, other investigators later proved that this approach provided a better survival and a lower myocardial infarction rate, with less angina pectoris. ${ }^{14-19}$

Some of these benefits can be found again in our study. In the patient group in which only sequential vein grafts were used (group II), a significantly shorter extracorporeal circulation time per distal anastomosis was seen. In the same group a signifi- 


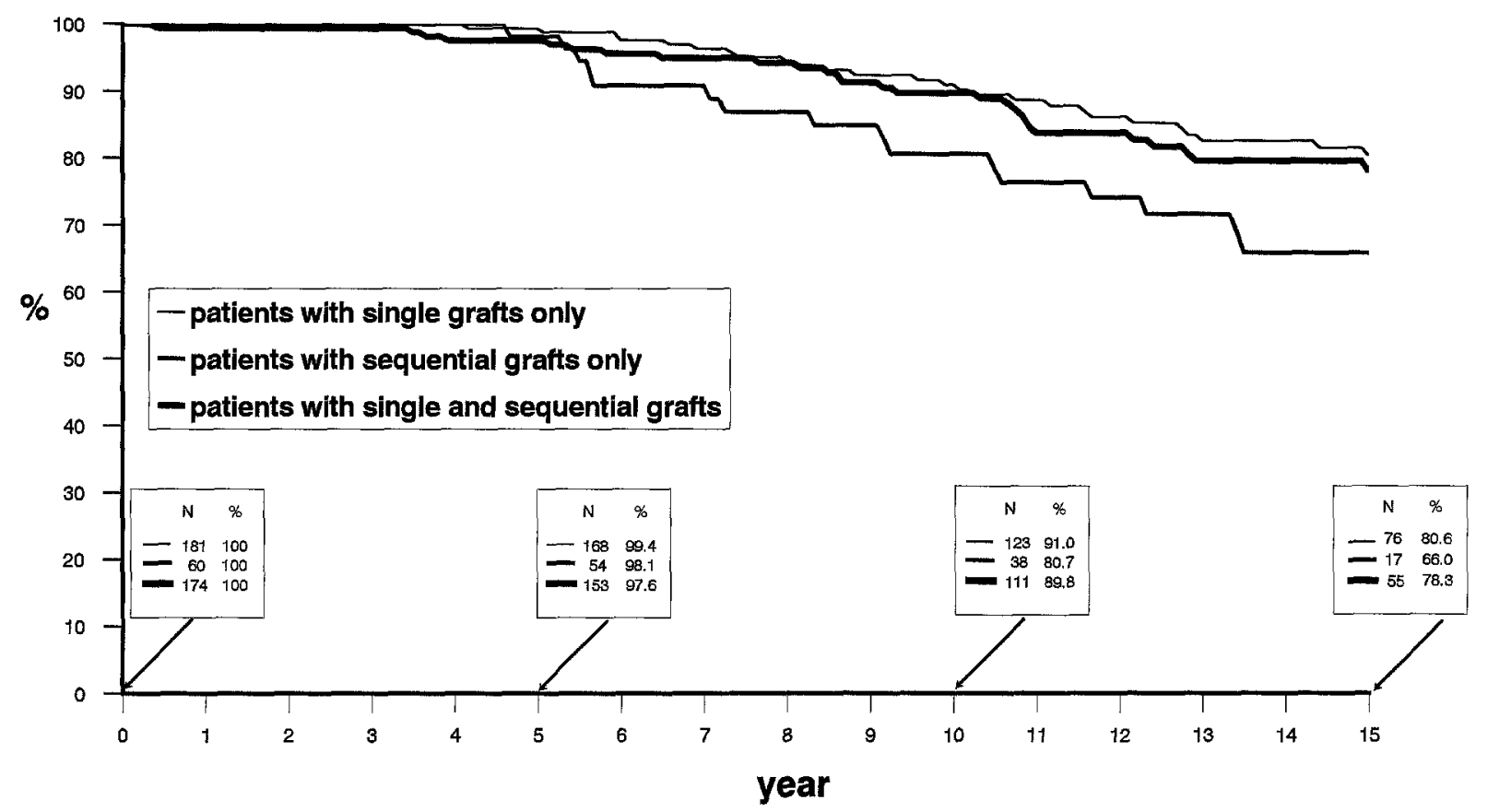

Fig. 2. Actuarial freedom from myocardial infarction in patients with single grafts only, patients with sequential grafts only, and patients with single and sequential grafts.

Table III. Results of multivariate analysis for myocardial infarction

\begin{tabular}{|c|c|c|c|}
\hline Factor & $H R$ & $95 \% \mathrm{CI}$ & $\begin{array}{c}p \\
\text { Value }\end{array}$ \\
\hline $\begin{array}{l}\text { Sequential graft (base }=\text { single } \\
\text { graft) }\end{array}$ & 2.06 & $1.08-3.93$ & 0.0293 \\
\hline $\begin{array}{l}\text { Single and sequential grafts } \\
\text { (base = single graft) }\end{array}$ & 1.26 & $0.73-2.18$ & 0.41 \\
\hline $\begin{array}{l}\text { Single and sequential grafts } \\
\quad(\text { base }=\text { sequential) }\end{array}$ & 0.61 & $0.33-1.15$ & 0.12 \\
\hline Age $(>50 \mathrm{yr})$ & 0.93 & $0.57-1.53$ & 0.78 \\
\hline Gender & 0.99 & $0.42-2.34$ & 0.98 \\
\hline $\begin{array}{l}\text { Obesity; Quetelet index }>25 \\
\text { (base }=\text { Quetelet index }< \\
25)\end{array}$ & 1.86 & $1.08-3.20$ & 0.0252 \\
\hline $\begin{array}{l}\text { No obesity; Quetelet index }< \\
25 \text { (base = Quetelet index } \\
\text { unknown) }\end{array}$ & 0.75 & $0.24-2.31$ & 0.61 \\
\hline Hypercholesterolemia & 0.84 & $0.44-1.59$ & 0.58 \\
\hline Cholesterol unknown & 1.23 & $0.32-4.76$ & 0.76 \\
\hline Hypertriglyderidemia & 1.71 & $0.94-3.09$ & 0.08 \\
\hline Triglycerides unknown & 1.53 & $0.46-5.10$ & 0.49 \\
\hline Unstable angina pectoris & 1.17 & $0.65-2.10$ & 0.59 \\
\hline
\end{tabular}

$H R$, Hazard ratio; $\mathrm{Cl}$, confidence interval.

cantly higher percentage of patients received complete revascularization.

On the long run, we found that the risk of cardiac events during follow-up was greater in patients with combined single and sequential vein grafts, and especially in patients with sequential vein grafts alone. Multivariate analysis shows that the risk of having a myocardial infarction or any event was significantly increased during 15 years of follow-up in patients with sequential vein grafts only. For a long time Bigelow and coworkers ${ }^{2}$ were the only ones reporting on long-term follow-up of coronary artery bypass with sequential vein grafts. The 3-year survival of 130 patients with sequential and single grafts operated on before June 1972 was $88 \%$. The survival of 71 patients who received multiple single grafts in the same period was $78 \%$. The hospital mortality of $6 \%$ for both groups was included in that 3 -year survival figure. In our study the numbers are 96\% (sequential and single grafts) and 98\% (multiple single grafts), not including the hospital mortalities of $4 \%$ and $0 \%$, respectively. Recently, longterm results of single versus sequential grafts of the Thoraxcenter in Rotterdam were reported by Meeter and colleagues, ${ }^{3}$ who divided their patients into a group with single grafts only and a group with mainly sequential grafts. The overall perioperative mortality was $1.9 \%$ and not different between the two groups. The survivals after 10 years in the two groups were $71 \%$ and $72 \%$, respectively. In our study these numbers are $85 \%$ and $79 \%$, but the Rotterdam study included only patients with three- 


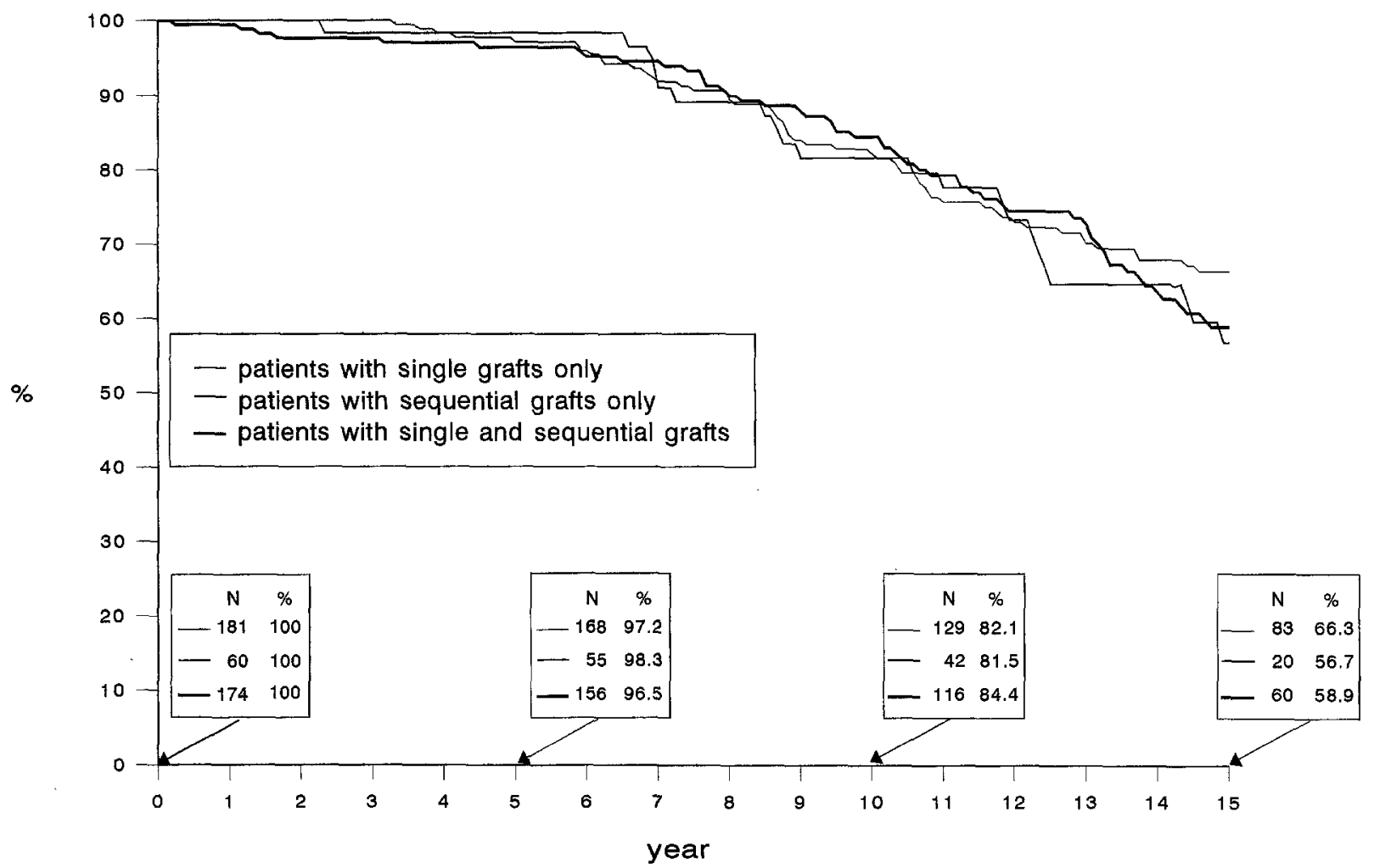

Fig. 3. Actuarial freedom from reintervention in patients with single grafts only, patients with sequential grafts only, and patients with single and sequential grafts. n.s., Not significant.

vessel disease or disease of the left main-stem coronary artery and depressed left ventricular function. As was the case in our study, the mortality in both groups in the Thoraxcentre study increased from the seventh year after operation, but there was no difference in survival between the two groups. Neither the need for reoperation or coronary angioplasty nor the frequency of angina pectoris between the groups was different after 10 years. The occurrence of myocardial infarction was not analyzed in that study. In an unpublished study, Sergeant and associates showed that sequential grafting was an incremental risk factor for survival, postoperative acute myocardial infarction, and the need for reintervention. $^{20}$

The results of our multivariate analysis surprised us. In view of the completeness of revascularization achieved in the patient group with sequential grafts only, we had expected their long-term clinical outcome to be better than that of the patients belonging to the other groups. A clear explanation for this result could not be found. It is true that the patients with sequential vein grafts were the first to be operated on with this new surgical
Table IV. Results of multivariate analysis for reintervention

\begin{tabular}{lccc}
\multicolumn{1}{c}{ Factor } & HR & $95 \%$ CI & $\begin{array}{c}p \\
\text { Value }\end{array}$ \\
\hline $\begin{array}{l}\text { Sequential graft (base = single } \\
\text { graft) }\end{array}$ & 1.22 & $0.73-2.03$ & 0.44 \\
$\begin{array}{l}\text { Single and sequential grafts } \\
\quad \text { base = single graft) }\end{array}$ & 1.10 & $0.75-1.62$ & 0.62 \\
$\begin{array}{l}\text { Single and sequential grafts } \\
\quad \text { (base = sequential grafts) }\end{array}$ & 0.90 & $0.54-1.50$ & 0.69 \\
$\begin{array}{l}\text { Age (>50 yr) } \\
\text { Gender }\end{array}$ & 0.74 & $0.52-1.05$ & 0.09 \\
$\begin{array}{l}\text { Smoking } \\
\text { Smoking unknown }\end{array}$ & 0.62 & $0.30-1.27$ & 0.19 \\
\hline
\end{tabular}

HR, Hazard ratio; $\mathrm{Cl}$, confidence interval.

technique. Therefore a learning phase for the surgeons could be expected. It is unlikely, however, that this would result only in the occurrence of a myocardial infarction during late follow-up. Moreover, none of the patients with only sequential grafts died during the operation, and only one patient had a perioperative myocardial infarction.

Since the time that our patients were operated on, 


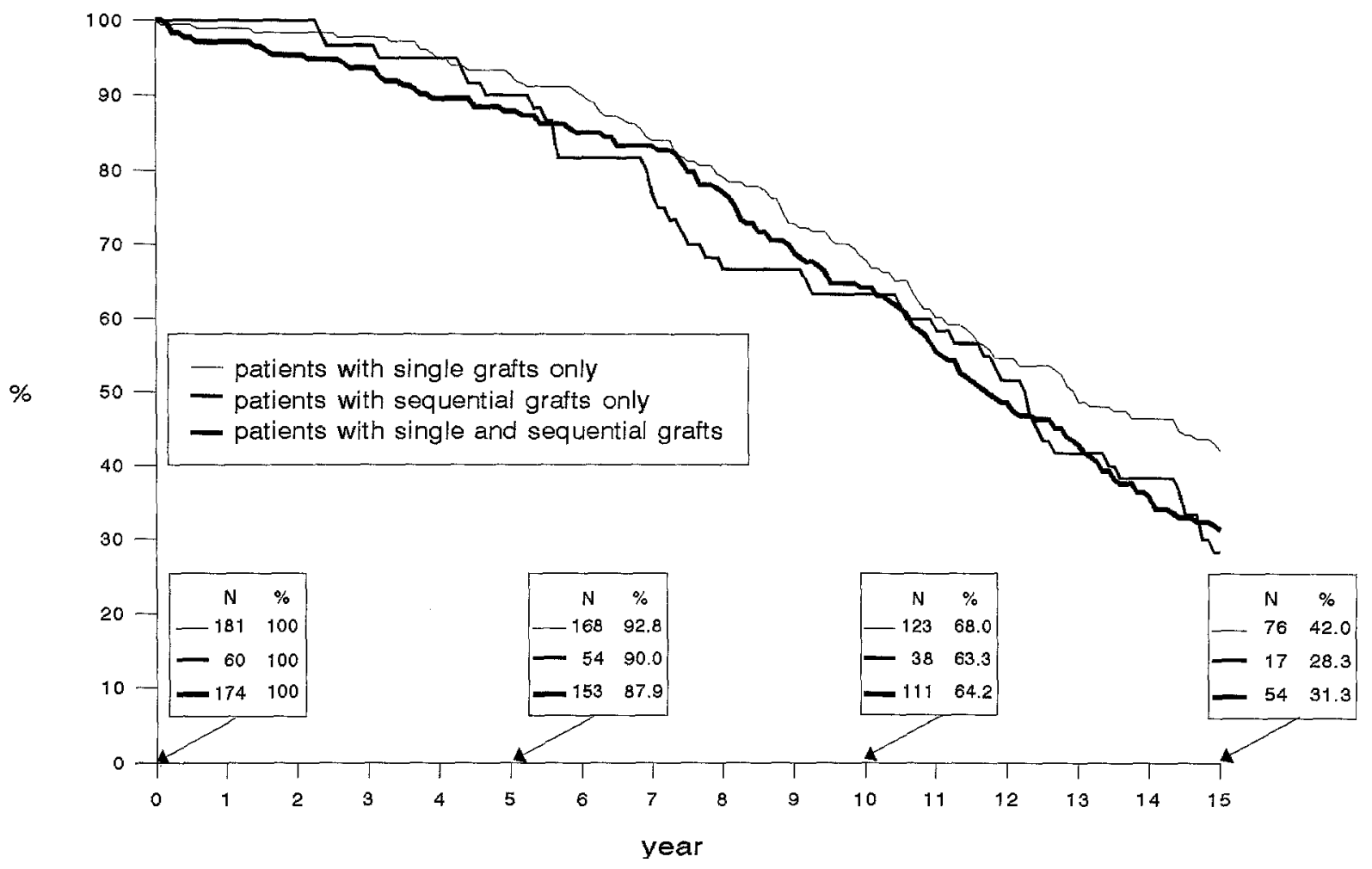

Fig. 4. Actuarial freedom from any event in patients with single grafts only, patients with sequential grafts only, and patients with single and sequential grafts.

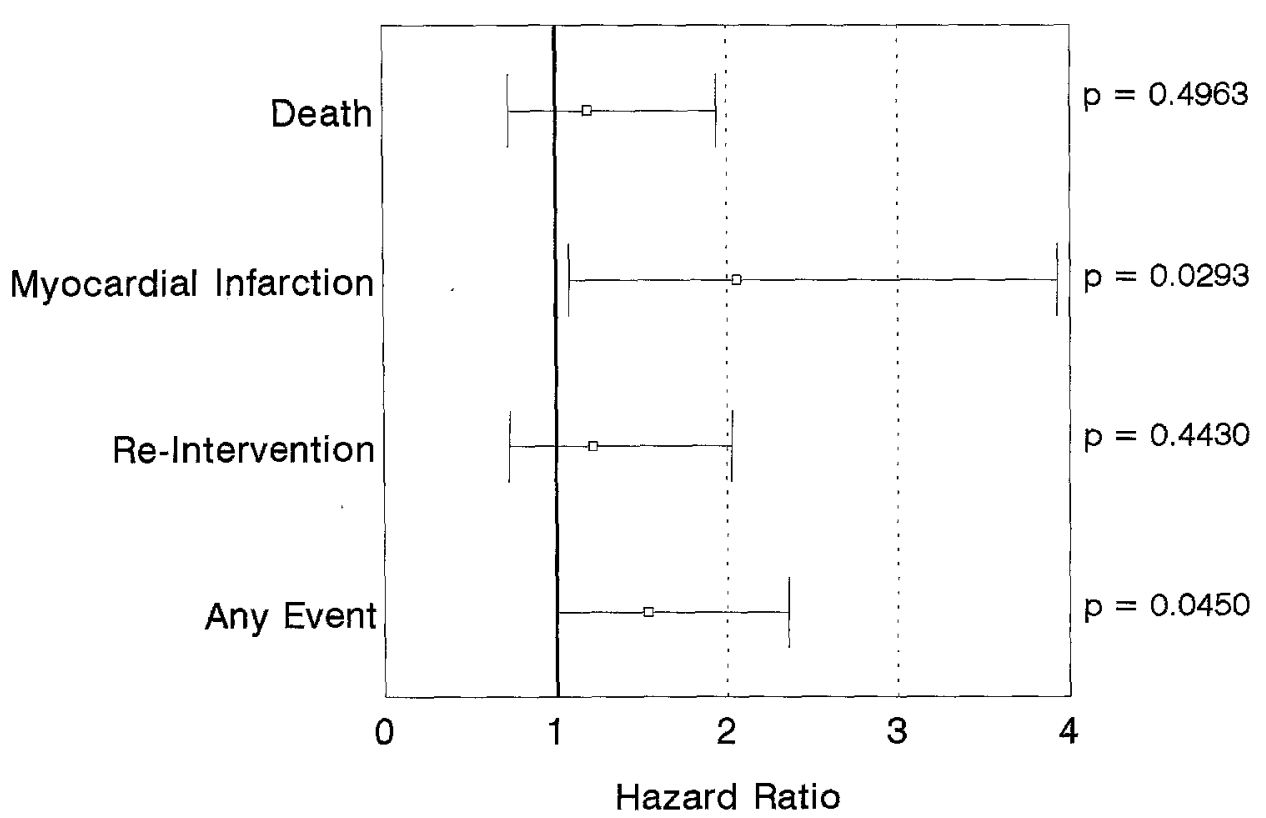

Fig. 5. Hazard ratio and $95 \%$ confidence limits and their statistical significance for different events between patient group with sequential grafts only versus patient group with single grafts only. 
Table V. Results of multivariate analysis for any

\begin{tabular}{|c|c|c|c|}
\hline Factor & $H R$ & $95 \% C I$ & $\begin{array}{c}p \\
\text { Value } \\
\end{array}$ \\
\hline $\begin{array}{l}\text { Sequential graft (base }= \\
\text { single graft) }\end{array}$ & 1.54 & $1.01-2.36$ & 0.0450 \\
\hline $\begin{array}{l}\text { Single and sequential grafts } \\
\quad(\text { base }=\text { single graft) }\end{array}$ & 1.25 & $0.91-1.73$ & 0.17 \\
\hline $\begin{array}{l}\text { Single and sequential grafts } \\
\quad \text { (base }=\text { sequential grafts) }\end{array}$ & 0.81 & $0.56-1.18$ & 0.27 \\
\hline Age $(>50 \mathrm{yr})$ & 0.99 & $0.76-1.28$ & 0.93 \\
\hline Gender & 0.86 & $0.56-1.30$ & 0.47 \\
\hline Two-vessel disease & 1.33 & $0.88-2.02$ & 0.17 \\
\hline Three-vessel disease & 1.57 & $1.00-2.46$ & 0.05 \\
\hline Diabetes mellitus & 2.18 & $1.01-4.67$ & 0.0459 \\
\hline Diabetes mellitus unknown & 0.88 & $0.64-1.21$ & 0.43 \\
\hline $\begin{array}{l}\text { Number of distal anastomo- } \\
\text { ses }(>3)\end{array}$ & 0.84 & $0.59-1.20$ & 0.33 \\
\hline
\end{tabular}

$H R$, Hazard ratio; $C I$, confidence interval.

much information has been published about the relation between the surgical technique of sequential bypass grafting and the angiographic patency. ${ }^{81-28}$ However, no direct relation between angiographic patency and clinical event rates has been provided, and no prospective randomized trial comparing coronary artery bypass with single versus sequential vein grafts has been undertaken.

Some critical remarks must be made about our own study. A disadvantage was that the patients in this study were not randomly assigned to receive either a single vein graft or sequential vein grafts. This decision may have been influenced by unknown factors that independently predicted clinical events. Second, clinical characteristics varied among the three groups, but with multivariate analysis we adjusted for these confounding factors. Through this statistical method we were able to show that notwithstanding the completeness of revascularization, significantly more patients with only sequential vein grafts had a myocardial infarction during follow-up compared with the patients belonging to the other two groups. Finally, inasmuch as the sample sizes were too small to allow subgroup analysis, it is possible that some types of sequential grafts provide good function.

In conclusion, our data add new information to the few published reports on the clinical outcome of coronary artery bypass with sequential vein grafts as compared with single vein grafts. We determined that the event rate is higher for the occurrence of myocardial infarction or any other event, although complete coronary revascularization had been achieved more often.

At present, sequential grafts continue to be used. However, the results of this study do not allow conclusions regarding circumstances mandating that sequential vein grafts not be used.

We thank Mrs. L. Jacobs, Mr. T. Voskuil, and Mr. C. van Cuyk for their support in the research and data collection.

\section{REFERENCES}

1. Flemma RJ, Johnson WD, Lepley D Jr. Triple aorto-coronary vein bypass as treatment for coronary insufficiency. Arch Surg 1971;103:82-3.

2. Bigelow JC, Bartley TD, Page US, Krause AH Jr. Long-term follow-up of sequential aortocoronary venous grafts. Ann Thorac Surg 1976;22:507-14.

3. Meeter K, Veldkamp R, Tijssen JGP, van Herwaarden LL, Bos E. Clinical outcome of single versus sequential grafts in coronary bypass operations at ten years' follow-up. J Thorac Cardiovase Surg 1991;101:1076-81.

4. van Brussel BL, Plokker HWT, Ernst SMPG, et al. Venous coronary artery bypass surgery: a 15-year follow-up study. Circulation 1993;88(Suppl):II87-92.

5. Kaplan E, Meier P. Nonparametric estimation from incomplete observations. J Am Stat Assoc 1958;53:457-81.

6. Cox DR. Regression models and life tables. J R Stat Soc 1972;34:187-202.

7. Collett D. Modelling survival data in medical research. London: Chapman \& Hall, 1994:192.

8. Grondin CM, Vouhé P, Bourassa MG, Lespérance J, Bouvier $\mathrm{M}$, Campeau L. Optimal patency rates obtained in coronary artery grafting with circular vein grafts. J Thorac Cardiovasc Surg 1978;75:161-7.

9. Cheanvechai C, Groves LK, Groves LK, et al. Bridge saphenous vein graft. J Thorac Cardiovasc Surg 1975;70:63-8.

10. Loop FD. Sequential coronary artery anastomoses. Ann Thorac Surg 1974;17:637-8.

11. Bartley TD, Bigelow JC, Page US. Aortocoronary bypass grafting with multiple sequential anastomosis to a single vein. Arch Surg 1972;105:915-7.

12. Sewell WH. Improved coronary vein graft patency rates with side-to-side anastomoses. Ann Thorac Surg 1974;17:538-44.

13. Sewell WH. Should we do $Y$ - and sequential grafts for coronary bypass? Ann Thorac Surg 1978;27:397-8.

14. Stiles QR, Lindesmith GG, Tucker BL, Hughes RK, Meyer BW. Long-term follow-up of patients with coronary artery bypass grafts. Circulation 1976;54(Suppl):III31-4.

15. Tyras DH, Barner HB, Kaiser GC, et al. Long-term results of myocardial revascularization. Am J Cardiol 1979;44:1290-6.

16. Loop FD, Cosgrove DM, Lytle BW, et al. An 11 year evolution of coronary arterial surgery (1967-1978). Ann Surg 1979;4:444-55.

17. Sheldon WC, Rincon G, Pichard AD, Razavi M, Cheanvechai $\mathrm{C}$, Loop FD. Surgical treatment of coronary artery disease: pure graft operations, with a study of 741 patients followed 3-7 yr. Prog Cardiovasc Dis 1975;18:237-53.

18. Vermeulen F, Alfieri O, van Brussel B, et al. Late results of complete versus incomplete revascularization. In: Bruschke 
A, van Herpen G, Vermeulen F, editors. Coronary artery disease today. Amsterdam: Excerpta Medica, 1981:285-95.

19. Jones EL, Craver JM, Guyton RA, Bone DK, Hatcher CR, Riechwald N. Importance of complete revascularization in performance of the coronary bypass operation. Am J Cardiol 1983;51:7-12.

20. Kirklin JW, Barratt-Boyes BG. Stenotic arteriosclerotic coronary artery disease. In: Kirklin JW. Barratt-Boyes BG, editors. Cardiac surgery. New York: John Wiley, 1986:285-381.

21. Grondin CM, Limet R. Sequential anastomoses in coronary artery grafting: technical aspects and early and late angiographic results. Ann Thoracic Surg 1977;23:1-8.

22. Moreno-Cabral RJ, Mamiya RT, Dang CR. Multiple coronary artery bypass using sequential technic. Am J Surg 1977; 134:64-9.

23. O'Neill MJ, Wolf PD, O'Neill TK, Montesano RM, Waldhausen JA. A rationale for the use of sequential coronary artery bypass grafts. J Thorac Cardiovasc Surg 1981;81:686-90.
24. Eschenbruch EM, Pabst F, Tollenaere P, Roskamm H, Schmutziger M. The significance of coronary topography for operative technique and tactics in multiple myocardial revascularization with jump-grafts. Thorac Cardiovasc Surg 1981; 29:206-11.

25. Crosby IK, Wellons HA Jr, Taylor GJ, Maffeo CJ, Beller GA, Muller WH Jr. Critical analysis of the preoperative and operative predictors of aortocoronary bypass patency. Ann Surg 1981;193:743-51.

26. Knaepen $P$, van Geldorp Th, Dekker F, et al. Sequential grafting of small vessels. In: Bruschke A, van Herpen G, Vermeulen F, editors. Coronary artery disease today. Amsterdam: Excerpta Medica, 1981:205-12.

27. Meurala H, Valle P, Somer K, Frick MH, Harjola PT. Patency of sequential versus single vein grafts in coronary bypass surgery. Thorac Cardiovasc Surg 1982;30:147-51.

28. Kieser TM, FitzGibbon GM, Keon WJ. Sequential coronary bypass grafts. J Thorac Cardiovasc Surg 1986;91:767-72.

\section{Bound volumes available to subscribers}

Bound volumes of The Journal of Thoracic and Cardiovascular Surgery are available to subscribers (only) for the 1996 issues from the Publisher, at a cost of $\$ 100.50$ for domestic, $\$ 128.94$ for Canadian, and $\$ 120.50$ for international subscribers for Vol. 111 (January-June) and Vol. 112 (July-December). Shipping charges are included. Each bound volume contains a subject and author index and all advertising is removed. Copies are shipped within 60 days after publication of the last issue of the volume. The binding is durable buckram with the Journal name, volume number, and year stamped in gold on the spine. Payment must accompany all orders. Contact Mosby-Year Book, Inc., Subscription Services, 11830 Westline Industrial Drive, St. Louis, Missouri 63146-3318, USA; phone 800-453-4351 or 314-453-4351.

Subscriptions must be in force to qualify. Bound volumes are not available in place of a regular Journal subscription. 